\title{
Online teaching in response to student protests and campus shutdowns: academics' perspectives
}

\author{
Laura Czerniewicz ${ }^{*}$ (D), Henry Trotter(D) and Genevieve Haupt
}

\author{
* Correspondence: Laura. \\ Czerniewicz@uct.ac.za \\ University of Cape Town, Cape \\ Town, South Africa
}

\begin{abstract}
During the period 2015-2017, student protests and university shutdowns rocked the higher education sector in South Africa, with key issues being raised regarding student exclusion based on financial, epistemological and cultural grounds. In this highly politicised and contested environment, some universities decided to use blended and online delivery as a strategy to enable the academic year to be completed and all curriculum to be covered, despite the disruptions. This was a controversial decision politically and a challenging one practically. From the perspective of the academics at the University of Cape Town (UCT), this paper draws on interviews with educators in three broad disciplinary areas to explore their views, practices, and experiences regarding the use of online materials in these unique circumstances. Activity Theory provides a framework to consider the issues systemically and to identify the tensions and contradictions in the system.
\end{abstract}

Keywords: Online education, Blended learning, Activity theory, Contestations, Protests, \#FeesMustFall, South Africa, University of Cape Town

\section{Introduction}

Whether or not technology is - or can be - neutral is a long-standing philosophical debate which inevitably infiltrates and underpins the fluid terrain of higher education in a digitised era. The impossibility of such neutrality is manifest in the role of technology in teaching, further amplified in a situation where technology is used during the highly politicized contestations of student protests. What is the responsibility of academics to the student body when protests interrupt classes and shut down the university? How do they manage their own principles, views and ambivalence when they have, and believe they have, an educational mission to complete the curriculum within a given timeframe? If teaching is to continue in a context of protest and disruption, how should it proceed - practically speaking - given the temporal, infrastructural, financial and emotional constraints that shape students' and staff responses?

These are the types of difficult questions that academics have had to answer when protests disrupt teaching, learning and examinations at higher education institutions (HEIs). In South Africa, between 2015 and 2017, academics faced this challenge as students at virtually every HEI in the country called for "free

(c) The Author(s). 2019 Open Access This article is distributed under the terms of the Creative Commons Attribution 4.0 International License (http://creativecommons.org/licenses/by/4.0/), which permits unrestricted use, distribution, and reproduction in any medium, provided you give appropriate credit to the original author(s) and the source, provide a link to the Creative Commons license, and indicate if changes were made. 
decolonial quality education ${ }^{1 "}$ and the cessation of exclusionary practices during the coordinated \#RhodesMustFall and \#FeesMustFall protests. "Whether seeking to participate actively and sympathetically, or not," one commentator noted, "all students and staff in the South African academy were part of the Fees Must Fall movement, in the sense that all had been affected by it. Their studies and employment had been influenced by protest actions and by institutional responses" (Hodes, 2016). Yet while South African students have long been known for their activism, these protests - coming more than 20 years after government change in 1994 - were notable for their power and persistence, as one university former vice-chancellor stated, "Even during the long, dark days of apartheid, no university had ever experienced this level of student protest in terms of scale, scope, intensity, and, in the course of time, violence" (Jansen, 2017).

First under the banner of \#RhodesMustFall initially and later \#FeesMustFall, the issues raised during the protests by many students - and some academics - pertained to student exclusion on cultural, epistemological and economic grounds. The responses from university management and academic communities in the different universities varied substantially. Perspectives were often polarised, while events were difficult to fathom as they unfolded.

The impact of these protests went well beyond the question of fees, however. At face-to-face-based teaching institutions such as the University of Cape Town (UCT), the disruptions impacted the entire educational enterprise. They affected the delivery of course content (such as the timing or even possibility of lectures and tutorials), the quality of tuition (as compromises had to be made against the standard level of provision) and the ability of students to prepare for end-of-year exams (which determine whether they pass or even graduate). The stakes were high for everyone, a fact which gave the protests their urgency.

Across the system, university leadership engaged to varying degrees with protestors' demands, while simultaneously considering and using measures that would allow teaching to continue or at least for the curriculum to be completed. This included employing private security and recommending academics utilise "blended learning" 2 to circumvent the effects of the disruptions. After one lengthy period of closure at UCT, the management announced, without prior planning or preparation, that, "Teaching and learning will resume through a variety of approaches, including blended learning. The precise combination will vary by faculty and discipline and will be communicated to students by their faculties and departments shortly." 3

As UCT's physical campus was closed for several periods from days to weeks during the three years, this directive was considered by the academics who wished to enable

\footnotetext{
${ }^{1}$ See for example https://www.news.uct.ac.za/article/-2017-07-27-preparing-sa-for-free-quality-decolonialeducation and https://blackopinion.co.za/2016/10/18/now-ever-free-decolonial-education-needed-southafrica/

${ }^{2}$ By "blended learning", we mean the use of both online teaching and learning methods in conjunction with traditional face-to-face classroom or laboratory engagements (sometimes called "hybrid learning").

${ }^{3}$ Max Price (14 October 2016), "UCT to resume 2016 academic year on Monday, 17 October 2016", https:// www.news.uct.ac.za/article/-2016-10-14-uct-to-resume-2016-academic-year-on-monday-17-october-2016. In an official communique the following day, Dr. Price referred to blended learning as "mixed teaching modes" and "alternative mixed mode and online methods", giving a sense of the varied nomenclature circulating at the time: https://www.news.uct.ac.za/article/-2016-10-15-vc-desk-further-details-on-completing-the-2016academic-year
} 
the required curriculum to be completed so that exams be written, even while they grappled with their responses to the issues underlying the protests. It seemed that most academics, no matter their views of the issues underlying the protests, favoured the completion of the academic year. (One university similar to UCT polled academics on this matter and found that the vast majority were in favour of a return to class.) A number of academics had already engaged in blended learning prior to these events. However, precisely because it reduced the protestors' greatest point of leverage against the university (i.e., the disruption of teaching activities), blended learning was also a controversial and very politicised form of teaching engagement. Initiated from the top as a stop-gap measure, it was also viewed as an inferior pedagogical strategy both compared to the usual form of face-to-face engagement and in terms of what it ideally should be. At minimum, it heightened the emotions surrounding the utility and prospects of blended learning beyond what it already elicited. ${ }^{4}$

Ultimately, the protests only came to an end when the national government decided to phase in tuition-free higher education for "poor and working-class South African undergraduate students" starting in 2018. ${ }^{5}$ This was a resolution that went far beyond what any individual institution could have delivered to the students; however, while it addressed the financial exclusion issues to some extent, the other forms of exclusion were left to individual universities to engage with.

After 2018, with "normal teaching" resumed at UCT (although not throughout the country $^{6}$ ), it became possible to reflect on the effects of UCT's blended learning intervention during the protests. In this paper, we assess how blended learning was used and understood by academics at UCT, exploring not only how it was operationalised in practical terms, but how academics felt about it in an otherwise face-to-face teaching environment. Employing activity theory, a systematic approach to qualitative interview data is taken in order to understand the tensions and contradictions that arose as academics engaged with (or considered engaging with) blended learning to complete their teaching goals for the year. ${ }^{7}$

\section{Context}

Since the end of apartheid, enrolments at South African HEIs have more than doubled from 495,000 in $1994^{8}$ to over 1.1 million in 2016 (DHET, 2018) and "student demographics at institutions of higher learning have changed dramatically in the last twenty years, with a significant increase in access for black students" (CHE, 2016). The student body became more heterogenous than in the apartheid era where universities were designed to be confined to specific "racial groups" and white universities best funded.

\footnotetext{
${ }^{4}$ See, for instance, the ways in which the steady revelation of educational technology controversies are being re-framed and minimized by the providers of that technology: Audrey Watters (18 December 2018), "The Stories We Were Told about Education Technology", Hack Education. Available at http://hackeducation. com/2018/12/18/top-ed-tech-trends-stories

${ }^{5}$ The Presidency (17 December 2017), "Free education for poor and working class students - The Presidency", http://www.politicsweb.co.za/documents/free-education-for-poor-and-working-class-students ${ }^{6}$ See for example https://www.timeslive.co.za/news/south-africa/2019-02-05-student-protests-at-ukzn\%2D\%2 Dwits-gain-momentum/

${ }^{7}$ A separate paper on the viewpoint of students to the blended learning intervention is anticipated. ${ }^{8}$ Karen MacGregor (21 June 2014). The massification of education in South Africa. University World News. Available at www.universityworldnews.com/post.php?story=2014062015083621
} 
Participation and success rates "remain sharply skewed by race and prior education; higher education in South Africa is a low participation system with high attrition" (ibid).

Yet, despite these complexities, "State contributions to university education declined from $49 \%$ at the beginning of the century to $40 \%$ by 2012 , while the burden on students increased from $24 \%$ to $31 \%$ during the same period." ${ }^{\prime 9}$ This shifting of the financial burden away from the state towards the individual student coincided with the South African government's greater acceptance of a neo-liberal understanding of higher education being more of a private good than a public one (Fitzgerald \& Seale, 2016). In addition, higher education funding competed against numerous other priorities - such as primary education, health care and social grants - leading the government to believe that it "could not prise open the doors of higher learning without serious consequences for the fiscus" (Ray, 2016).

By 2015, the first year of the \#FeesMustFall protests, the collective amount of historical student debt owed to universities was already in the billions of Rands (R9 billion in 2019), ${ }^{10}$ disproportionately affecting poorer students and their future prospects. Towards the end of that year, in October, students at universities across the country started to call for the abolition of tuition fees for all students of higher education. It spread from the University of Witwatersrand in Johannesburg to UCT (where students were emerging from their own \#RhodesMustFall protest success) and then to other South African universities. As in years past, protestors focused their efforts during the end of the year close to exam time, maximizing the impact of their disruptions. In response, the government promised that there would be no fee increases for 2016, a move that temporarily reduced the intensity of the protests. University responses to disruptions and violence varied according to circumstances and leadership strategic choices. Private security were brought in to a greater or lesser extent, this being an emotive decision for those both in favour and those against it. "Institutions like UCT went out of their way to avoid a security response, closed their academic programmes early, and even postponed some of their teaching and examinations to the new year" (Habib, 2019). The university management negotiated at length with protesting students, often through the night, expressing the hope that engagement through dialogue rather than force would be effective. Perhaps ironically, the more "securitised" universities were able to complete their curriculum on time, often in extreme conditions. UCT had to defer exams to the first month of the following year.

Meanwhile, the national Presidency initiated the Heher Commission to look into the feasibility of various funding models for higher education. The lengthy report that was released towards the end of 2017 soberly concluded that "there is insufficient financial capacity in the state to provide totally free higher education and training to all who are unable to finance their own education, let alone to all students, whether in need or not" (Heher, 2017). Despite this conclusion, and seemingly without consulting with his own Minister of Higher Education and Training (or the Treasury), the then-President Jacob Zuma surprised everyone by announcing that all students from poor or working-

\footnotetext{
${ }^{9}$ PricewaterhouseCoopers (30 July 2015). Funding of public higher education institutions in South Africa. Available at www.pwc.co.za/en/publications/funding-public-higher-education-institutions-sa.html

${ }^{10}$ Bongekile Macupe (15 Feb 2019). Old debts cost universities dearly. Mail \& Guardian. Available at https:// mg.co.za/article/2019-02-15-00-old-debts-cost-universities-dearly

${ }^{11}$ This was done in a graduated fashion, applying in 2018 to all eligible first-year students; in 2019 to firstand second-year students; in 2020 to first-, second-, and third-year students; and so forth.
} 
class backgrounds (whose parents earn less than a combined total of R350,000 per year) would receive tuition-free education starting in $2018 .{ }^{11}$

At the same time as these tumultuous events were taking place in South African higher education, blended teaching and learning methods had been growing globally. In line with this trend, the use of educational technology and blended learning had gradually been increasing at UCT as well, often the result of individual lecturers' decisions or the changing norms of educators' departments or disciplines (Czerniewicz \& Haupt, 2018). But, as mentioned above, with the disruption to teaching and exams that occurred from 2015 to 2017, the UCT management decided that blended learning was a strategy to be utilised by academics to help complete their teaching obligations for the academic years. As the vice-chancellor shared publicly through the media: "Faculties agreed to use blended learning strategies to complete the interrupted semester." 12

Hence, the context in which blended learning was officially promulgated by the UCT management ensured that it was politically charged, far more than it ever had been before. Since it was enlisted by the administration as a tool to overcome the disruptive effects of the protests, it shaped the way that both academics and students understood it in their interactions with each other.

\section{Literature review}

The process of researching, writing and sense-making regarding South Africa's \#FeesMustFall student protests and university shutdowns is relatively recent, with little consensus emerging, reflecting the contestations of the events themselves (see for example, Badat, 2016; Booysen, 2016; Chikane, 2018; Habib, 2019; Jansen, 2017; Ngcaweni \& Ngcaweni, 2018).

While there has been an academic interest in the role of social media and the student protests (e.g. Bosch, 2016), research has not focused on the nature and implications of online education to deal with the impact of institutional disruptions. There is certainly an existing body of literature on the ways in which the uncritical embrace of technology traps universities in a neoliberal, techno-determinist paradigm (Hayes and Jandrić, 2014) as well as a scholarly community framed as a "critical pedagogy" where online learning is not only dissembled but can also be used as a form of resistance (Boyd, 2016). This literature has been explicit in its advocacy for educators to engage in a deep and critical exploration of the relationship between the digital sphere and online pedagogy, in order to "cultivate connected, participatory educational development that crosses institutional and national boundaries, and which takes equity, social justice and power differences into consideration, promoting educator agency" (Bali \& Caines, 2018). In South Africa, there is also scholarship theorising how new technologies are implicated in new forms of digital neocolonialism linking colonial pasts and neoliberal futures (Adam, 2019).

During the protests, the campus shutdowns and VC's call for using blended learning as a stop-gap measure temporarily short-circuited those deliberations, given that the exigencies of the moment demanded immediate action with little time for reflection. Indeed, in the interviews that follow, many academics reveal great ambivalence about

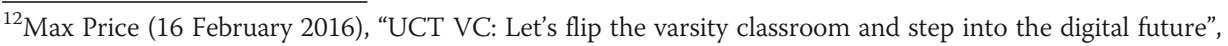
Mail \& Guardian Online, https://mg.co.za/article/2017-02-16-00-flip-varsity-lectures-for-equal-success
} 
their use of blended learning during the protests, noting that, despite the practical utility it offered in "delivering" curricular content and exam preparation materials within tight timelines, they typically felt that it was unsatisfactory as a solution to the issues they were confronting. In addition, although research and experimentation with blended learning had been taking place for some years in South Africa, it was only in 2014, a year before the protests, that the national regulatory frameworks allowed traditional residential universities to offer fully online distance programmes. Thus academics had had little time before the shutdowns to wrestle with the pedagogical, cultural and epistemological implications of going online before being informed that they should do so. The circumstances in which this was thrust upon them were unstable, unplanned and uncoordinated.

Beyond South Africa, there is a small body of literature on the use of blended and online education in unstable learning environments. This includes the use of educational technology in response to displacement, such as through the Syrian conflict (Tauson \& Stannard, 2018; UNESCO, 2018); or natural disaster, such as through the floods following Hurricane Katrina (Hoover, Dopson \& Drehobl, 2010). In the wake of the Christchurch earthquakes of 2010 and 2011, academics at the University of Canterbury in New Zealand adopted technologically enhanced teaching practices - what they called "resilient blended learning" - to ensure that teaching could proceed despite significant disruption, dislocation and displacement (Mackey, et al., 2012; Tull, Dabner \& AyebiArthur, 2017). In their reflections on the new practices that they engaged with, Mackey et al. (2012) asserted that, "Creative and innovative solutions are required if a sound academic program is to be maintained when faced with a lack of space and physical resources, interrupted schedules, dispersed students, and an extended period of civil emergency" (130).

In all of these contexts there would have been consensus regarding the nature of the crisis and the need for innovative responses, including the virtual. In conflicts, disasters and protests which can lead to educational disruptions, the responses to them are bound by specific ethical imperatives. In the wake of mass displacements and natural disasters, both students and academics are typically keen to find a way to resume educational activities as soon as feasible, as these events are understood as an undesired intervention into a desired educational ambition.

The South African case is unlike these in context, strategy and ethics: it seems unique with no other country studies of such use of technology during protest-induced university shutdowns having been identified. Within the country, a nascent literature has emerged regarding academics' teaching and learning decisions made at different universities (Czerniewicz \& Haupt, 2018; Kilfoil, 2018; Meintjes, 2018; Tekane, Louw \& Potgieter, 2018). Thus, despite all being state-funded institutions, their differing histories, capacities and strategies profoundly shaped how or whether blended learning formed part of that response.

For instance, at the University of Pretoria, where three campuses were shut down for extended periods, many teaching activities went online virtually "overnight", exemplifying their lecturers' "resilience" (Potgieter, et al., 2018; Scheepers, et al., 2018). Meanwhile, at the University of Johannesburg, where protests were forcefully contained by the administration, the mild disruptions "did not lead to massive changes in blended learning", but rather small "tweaks, and a continuation of the 
slow move towards blended learning" that had started before the protests (de Wet, et al., 2018).

What is clear then is that the disruption of teaching is a strategic action, and some academics argued that the issues raised by protestors be addressed before teaching resumed. Thus, using technology is itself a strategic response where teaching is politicised and implicated in a complex moral web (Swartz, Gachago \& Belford, 2018). The contexts raised important different ethical dilemmas, even as blended learning possibly provided practical or pragmatic solutions to the completion of the academic year.

\section{Methodology}

To study this unique situation, funding was sought and received from the Carnegie Corporation for four universities to investigate blended learning during the protests: the universities of Cape Town, Johannesburg, Free State and Pretoria.

At UCT, interviews with academics, students and professional staff were conducted regarding their experience of and feelings about the blended learning intervention. This paper reports only on the academics. However, finding educators at UCT who were prepared to be interviewed proved to be difficult. As this was a demanding and stressful time for academics, it was only possible to recruit a small number of interviewees. A total of 16 academics from three departments were interviewed, these being in the faculties of Commerce, Engineering and Humanities.

Potential interviewees were approached by emailing previous participants of institutional teaching and learning events. They were also identified and approached through departments which had run training sessions for academics who wanted to make sure that, if they did use blended learning to cope with the disruptions, they would at least be able to do so effectively. The sample was therefore skewed towards those with some existing interest in blended delivery as well as some prepared to consider it.

After ethical clearance was granted by the relevant faculty and academics agreed to be interviewed, one-on-one interviews were recorded, transcribed, then coded and analysed using a theory-led approach.

\section{Conceptual framework}

The study draws on Cultural-Historical Activity Theory (CHAT) to delineate the key elements of UCT's blended learning "activity system". Once identified, the study then uses CHAT to assess the tensions and contradictions within the activity system. In brief, according to CHAT, an activity system represents how subjects' action towards a specific object to achieve a given outcome is mediated by tools (physical and symbolic), rules (formal and informal), communities (participants and stakeholders) and a division of labour (Engeström, 1987). It helps identify where obstacles occur in a system so that can they can be analysed, altered and overcome. This process is iterative as changes in an activity system typically create new tensions and contradictions within it.

In Fig. 1, a CHAT triangle offers diagrammatic expression of an activity system. The triangle shows how the various nodes (tools, rules, community, and division of labour) 


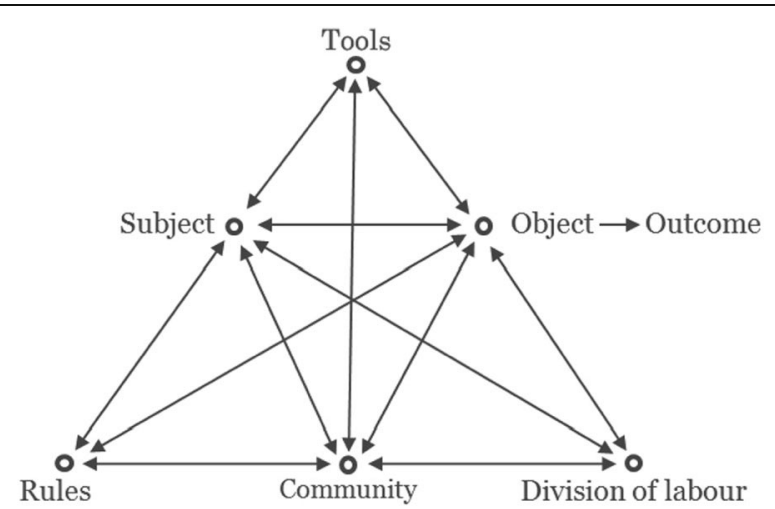

Fig. 1 CHAT Triangle representing an activity system

mediate subjects' action towards an object and outcome. In the analysis that follows, it will become clear how the CHAT approach allows us to gain a systematic view of blended learning at UCT during the student protests.

\section{Analysis: UCT's blended learning activity system}

In this section, we analyse UCT academics' feelings about and deployment of blended learning mechanisms during the university shutdowns. In Fig. 2, we use the nodes of the activity system triangle to organise the analysis which will help clarify tensions and contradictions in this system.

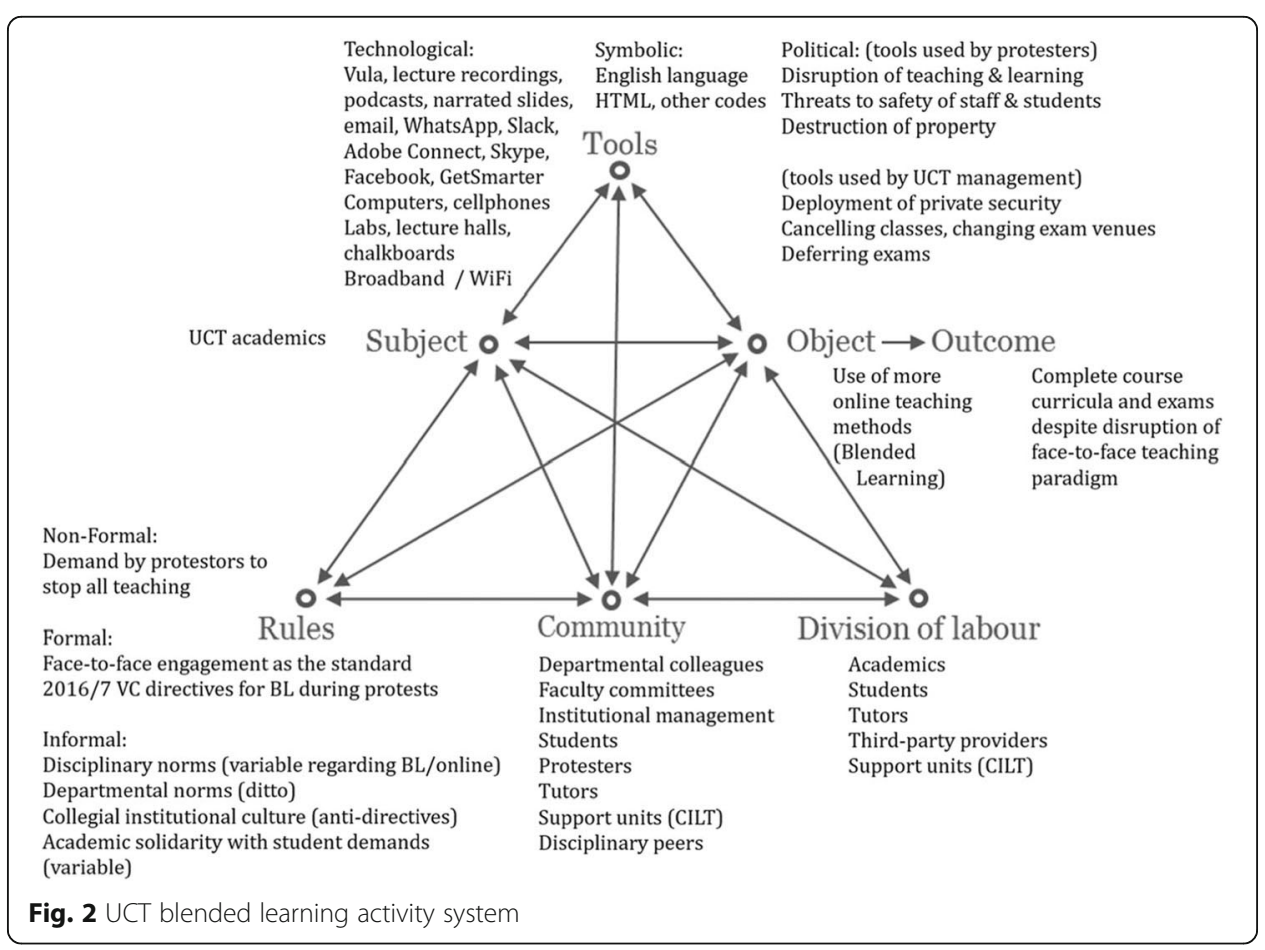




\section{Subject, object, and outcome}

The subject in this activity system were UCT academics whose object was to use more online teaching methods (blended learning) to ensure completion of their course curricula and exams for the year (the outcome), despite disruptive student protests. This was an activity system in which all UCT academics were involved one way or the other, though for the purposes of this analysis, it will only refer to the ones who were interviewed here.

Though academics always seek to complete their course curricula and exams in a given year, this particular activity system emerged in the context of the student protests which threatened to impede that desired outcome. Thus the object discussed here - of using blended learning techniques to complete the curriculum - assumed far greater urgency and controversy than it normally would have because it was deployed to circumvent the desires of many of the protestors, and possibly some of the academics themselves.

For most academics interviewed, blended learning was generally considered a legitimate pedagogical supplement to their traditional face-to-face activities. Though most preferred face-to-face teaching (which they argued befits a residential university), many had already incorporated some blended learning into their courses. Thus when the formal directive was given by the management, one academic said that, "my course is sufficiently blended that moving to online wasn't a big step for me or for the students" (Respondent 6). Another suggested that this was likely the case for most staff: "In a sense UCT is a blended learning institution now because we have [the learning management system (LMS)] and we record our lectures, we do that standardly. We make announcements, we provide resources online and so there is a blended learning" (Respondent 11).

However, while many academics had already been engaging in blended learning - to save students money, because students liked it, and because it added pedagogical diversity and richness to their teaching - they had never done so for the sake of overcoming disruptions caused by student protests. This immediately politicized blended learning, opening new reasons to engage with it, or not.

With classes disrupted or cancelled, academics had to face the possibility that they wouldn't be able to complete their coursework curricula before the end of the term, which would have knock-on effects into the next year. Blended learning offered a (controversial) way for academics to deliver the curricula to their students in a timely manner.

For a number of academics, the call for blended learning provided just the tool needed for overcoming the disruptions. As Respondent 2 stated, "on the whole we managed to achieve all the course outcomes that we needed to do in the online space". Another said that "it was generally quite positive, the students were happy that we tried to push through the shutdown in terms of supplying lectures" (Respondent 9).

Indications are that, most students did engage with the blended learning interventions towards the end of each year, suggesting that while many supported the protest for free education, they did not necessarily want their own educational careers to stall for a lack of participation in sanctioned online lectures and exams. (This is similar to the wishes expressed by the students at UCT's most comparable South African university, the University of Witwatersrand, where $77 \%$ of students voted for the resumption of classes after a lengthy campus shutdown. ${ }^{13}$ ) Thus we must be careful not to conflate

\footnotetext{
${ }^{13}$ eNCA (30 September 2016), "More than 77\% of Wits students want to return to class: poll”, https://www. enca.com/south-africa/wits-student-poll-interim-results-released.
} 
the term "protestors" with "students", as these were both diverse configurations socioeconomically, politically, and in terms of their strategic sensibilities.

In the cases where the curricula were delivered on time, academics wanted to make sure that students had the necessary materials for exam preparation. This would have normally been delivered in the classroom or laboratory, but, as Respondent 10 stated, "because the students didn't want to come onto campus, we have told them that we will put something up on [the LMS] as an exam preparation". This was the typical approach, to upload materials onto the platform with notes on how students should engage with them for the sake of exam prep. As Respondent 16 related, "because we didn't have the face-to-face lectures, I think there was a lot of emphasis on preparing them for the exam through [the LMS] and giving tips and saying, 'read this and don't read that,' or, you know, 'focus on this content and you can leave this out', or 'this is examinable and this isn't'".

While blended learning offered greater utility for academics who may have not used it before, or were seeking strategies for overcoming curriculum delivery challenges, for many others it was not necessary. Since the protests occurred towards the end of 2016 and then 2017, some teaching for different courses had already been completed just prior to the disruptions. But academics also learned from the 2016 experience, thus they anticipated disruptions and planned for it in 2017, as Respondent 4 relayed, "as much as I detest the word 'frontloading', there was a careful engagement with the material on the course to ensure that students were able to engage with the material earlier on", so that students wouldn't require any face-to-face engagement after a certain date.

That comparative experience from 2016 also taught some academics that blended learning doesn't work for them. Respondent 7 stated that, "after last year when the blended learning didn't really work in our estimation, there wasn't much of an appetite to do much of it this year". Part of the reason for this was that it changed the type of accountability protocols between the academics and the students. Respondent 2 believed that, "because there were no formal lectures, they [students] were all just on holiday and it does worry me that that is how a lot of students see that, just because 'there is no lectures, [so] we don't have to do anything"'.

In addition, some academics questioned the very object of the activity system, the use of blended learning. Even though most of them engaged in blended learning at some level during the protests, virtually all of them thought it was inferior pedagogically to a face-to-face mode of learning. At best, it was a second option, not the ideal. They gave a host of reasons detailing their ambivalence.

First, they believed that students learn better through personal engagement with each other and with the lecturer. As Respondent 3 explained, "I remain firmly of the view that [blended learning] is very much the second best. You can see in the way that students respond, in the way they pick up knowledge, in the interaction and debate and all the kind of things, and say what you like, you cannot replicate that on an online system".

Some were more cynical, complaining that a lot of online tools were gimmicks. As Respondent 3 said, "everyone I have spoken to says, 'Ah, this chat room is a wonderful tool'. It is a damned waste of time, I have never seen such inane exchanges!" He continued, blasting online learning with a rhetorical question: "Would you be prepared to go to a doctor that had done online education?!" 
Second, they suggested that online learning creates a different set of accountability protocols that are less effective than face-to-face. As Respondent 8 stated, "I don't think blended learning is very good for undergrads. I think undergrad students need the discipline around coming to lectures and that interaction and also the social activities that happens in the classroom".

Third, they claimed that the students themselves don't like blended learning as much. “They didn't like the computer screens all the time. And they definitely do prefer faceto-face" (Respondent 15). Indeed, "they want community, you know" (Respondent 9). And, in any case, "students cannot watch a 45-minute lecture. They can't sit at home on their beds and watch that lecture from beginning to end and find it sufficiently stimulating" (Respondent 2).

Fourth, academics argued that many students require the kind of personal attention and feedback that could help them overcome their challenges: "People here are very aware that our students need personal attention and need a lot of tutoring, a lot of attention to writing skills and so, a lot of remedial work even on the first or second year basis of coming out of a school system. So online teaching in itself I think is viewed maybe not very enthusiastically, with scepticism given our context and given the type of work that we teach" (Respondent 7).

Fifth, some academics noted declining engagement and performance, suggesting that it, as a mode of teaching, was not optimal. Respondent 11 said, "My sense is that there was pretty low engagement with those online resources, which is why we didn't try and repeat the same approach because it was quite intensive from our point of view". Indeed, as Respondent 2 averred, "I think generally we have seen possibly slightly declining performance across our courses when we have moved urgently into the blended space because students have lost out on a lot of that kind of contact that we always have".

Summing up these critical responses, Respondent 6 noted with concern, "I think we potentially are losing some graduate attributes .... I worry that we have lost a bit of that 'graduateness' in this mad scramble to fit content into online spaces and make it happen".

However, while most of the interviewees felt that "blended learning is a bit of a Band-Aid being stuck over a much bigger problem" (Respondent 7), a few saw its virtue in terms of adding to pedagogical diversity. As Respondent 16 said, "The main advantage with the blended learning approach is that it adds a real richness and diversity to your course content that I think makes it really come alive for students .... You can give them what they would have gotten in the face-to-face space but you can also make it such a more multi-dimensional experience with things like photographs or video or audio ... [giving] more value for money".

But aside from a couple of blended learning enthusiasts, the majority tried to find that middle point between scepticism and optimism. "I think for the students it's good to expose the different kinds of learning, but I think it definitely must be in balance, so with the face-to-face and then this as a different way of doing things, but in balance" (Respondent 15).

However, if there were concerns about the pedagogical utility of blended learning, there was also a question of whether that was what academics were actually doing. Many suggested that most staff were just "putting stuff online" rather than engaging in a pedagogically rigorous activity worthy of the name, such as Respondent 6 who said, "Let's call that an online presence before it is even blended learning, just normal 
teaching we do that". Or, as Respondent 7 put it more matter-of-factly, "I think that people just felt they could just upload notes and that is what I think what most people did".

Thus, while many thought it was disingenuous to conflate their online activities with what they considered to be "real" blended learning, they understood why this was the case, given the unique circumstances. As Respondent 4 explained, "to try and nuance that message [of blended learning] in a time of crisis is impossible, OK. You can't nuance it, you can't. So what you got to do is you got to use a term which people understand or can latch on to, can run with, that means close enough to what is happening without actually describing in reality what it is, because people won't accept the reality of what it is". In this sense, "blended learning" was a convenient shorthand for describing the variety of online activities undertaken in response to the protests.

What this reveals is that, even before we have discussed how tools, rules, community stakeholders and the division of labour mediate action in this activity system, we see that there was nothing straightforward for academics in the decision to engage with blended learning in order to complete the academic year.

\section{Tools: symbolic, technological and political}

Academics' activity regarding blended learning was mediated by a number "artefacts", namely symbolic, technological and political tools. The symbolic tools are primarily the English language, which is the language of instruction at UCT (and a second or third language for many students and faculty members). It also includes computer-related coding languages such as HTML and CSS. These tools were not unique to this activity system, however, as they would be standard symbolic tools in most UCT-related activity systems.

The more obvious set of tools mediating activity in the context of online blended learning was technological, referring to the programs, platforms, apps, hardware, software and digital affordances used to carry out blended learning. These included UCT's online learning platform, third-party provider sites, social media and connectivity apps, online collaboration platforms, presentation software, digital teaching formats (such as lecture recordings, narrated slides, podcasts), as well as formal traditional institutional infrastructure (chalkboards, laboratories, lecture halls) and technical infrastructure (broadband, WiFi). Some of these would be relevant across multiple activity systems, but they played a key mediating role in this one as they were essential in the deployment of blended learning.

The most commonly used site to handle blended learning was the LMS, a UCT platform that allows for a multitude of digital files to be uploaded on it for student engagement. It also has forums and chatrooms that can be used, though most academics used it for hosting lecture recordings, lecture notes, podcasts, additional materials, past exam papers and narrated slides.

The other set of tools that mediated action were political ones. These were the disruptions of teaching and learning activities at the university by protestors, which included blockades at university entrances, the closing down of lectures in progress, the repeated setting off of fire alarms, and, in some instances, the destruction of equipment. These took place even before official institutional closures. 
For those who managed to complete their teaching before the disruptions, its impact was minimal. Some of this was achieved due to the normal rhythms of the course, but in other cases because of frontloading - "we shifted everything to the first three quarters" (Respondent 8) - in anticipation of the disruptions.

But for the majority who were still teaching and conducting exams, it had serious curriculum repercussions. Sometimes academics could not teach key concepts which required they then change the tests. As Respondent 9 shared, "We couldn't teach that [particular concept], that was what we lost 2016. So we had to then also change the exam. It was a disaster". Others had to push materials from the end of one year to the beginning of the next, when an additional teaching period was inserted before the next academic year began.

The most memorable impact that the protests had on the academics interviewed was their sense of morale. As Respondent 2 shared, by the end of the year, "I was just about in tears, I was so exhausted .... I think because we had been so determined that there would be no sacrifice, everyone has just had to work so hard .... It is tough when, you know, in the middle of a residential thing, suddenly to be doing everything online". Virtually every interviewee stated one way or another that academics were "completely and utterly demotivated" by the protests and the efforts they had to make to adjust their teaching.

Another strategy deployed by the institutional management was the use of private security particularly to protect exam venues, which it was noted added to the "high stress environment" (Respondent 12). In general, the academics interviewed were critical of the management's response to the shut downs. They believed the executive did not realize how damaging it was to teaching quality, and to the mental and emotional wellbeing of the staff and students. As Respondent 11 shared, "In the weeks where there have been disruptions, I think that the university is a complete mess and our students are being failed in a massive way and frankly I don't think that the university executive understands how bad it is at all. I think they have no clue, because I think if they had a clue, they would have found ways to stop these disruptions".

\section{Rules: formal, informal and non-formal}

The activity system is mediated by a number of complementary and competing formal rules, informal norms and extraneous non-formal demands. As a residential university, the primary formal pedagogical rule is for educators to teach in a face-to-face manner. However, as discussed above, during the protests, when this teaching style was purposely disrupted, the Vice-Chancellor issued a directive to the university telling educators to start using online blended learning strategies to get around the disruptions. As a formal rule, this was something that all educators had to respond to at some level.

We have already seen how academics responded to the general situation, with many having already incorporated blended learning into their teaching while others added more where they could. A few, as well, declined to engage with it at all (as we will see below). In other universities, the VC's directive might have led to a massive reorganization of institutional activities, but at UCT, academics did not interpret it as a hard "rule", but a signal of intention from the management that it is more serious about blended learning (now that traditional learning has been disrupted). Academics took note of the directive but only as but one of many other competing factors. 
The key reasons for this are, first, UCT has what has been described as a "collegial" institutional culture (Czerniewicz \& Brown, 2009; Trotter, et al., 2014) where academics enjoy a great deal of autonomy regarding teaching decisions. They typically do not respond positively to executive mandates (which might be more acceptable at universities with "managerial" institutional cultures). If a change in direction is required, they prefer lengthy periods of consultation because they value their autonomy. That is why a number of academics voiced their displeasure with the approach, with Respondent 16 saying, "it just felt like it was something forced on us". Respondent 7 went even further, stating, "everybody would be keen to explore those [blended learning strategies] if it wasn't with a sort of gun against your head".

Second, academics' actions at UCT are also mediated by the informal norms of their departmental and disciplinary peers regarding online learning. In some departments and/or disciplines, blended learning is common (thus the directive added little pressure or burden). But in others, such as those that rely on laboratory time for optimal learning, the directive was more difficult to instantiate. In fact, some felt such a campus-wide directive was insensitive to the specific norms guiding their teaching practices, and even the broader national context, as Respondent 7 argued: "you cannot just transplant these methods, pedagogies from elsewhere to South Africa because we are a very different context, so it is definitely not a onesize-fits-all type of approach".

The reception to such guidelines from the departmental level was received with more enthusiasm because these had been developed with greater input from faculty members themselves. As Respondent 1 said, her department advised academics to "make your plans. It might be as early as next week that we have to move online. We will not stop teaching .... If we stop face-to-face teaching, you will continue with some sort of online plan. We must finish, we cannot delay the end".

Another reason why academics felt free to question the executive-level directive was that, in their opinion, they weren't really being asked to do "blended learning" anyway, but rather just "throwing things into the wind" online. Respondent 4 complained:

Blended learning is a deliberate activity where the activities in the class and in the course are structured in such a way to make use of the various opportunities of time in the way that is most constructive for the students, OK. It has got nothing to do with panic throwing things online. It has got nothing to do with what happened at the end of this year. That is a complete disservice to anybody who actually engages in blended learning. It is an abomination, OK, to suggest that what we did was blended learning.

Thus the directive opened up a pedagogical debate as to the merits of calling their activities blended learning or not. Many felt, like Respondent 3, that there was "no academic reason for it", that they were just placing their normal teaching materials online for students to access, which, for them, is not actual blended learning.

Lastly, the protestors issued a non-formal demand of their own, that all teaching should come to a halt. There should be no classroom teaching and no online blended learning. As Respondent 12 viewed it, "you can see on social media, the protesters hate the idea of blended learning and, in their opinion, this place should be a ghost town, we should all go home". Though this went against the formal directive of the $\mathrm{VC}$, 
academics had to weigh the consequences of going against the protestors' demands, and also decide where they stood on these contradictory "rules".

Many academics were sympathetic to the demands of the protestors for free decolonial quality education, and there was particular concern regarding the financial burden for poor students; yet they (like many students) still thought it important to complete the coursework in the normal timeframe so that exams could take place by the end of the year, allowing students to graduate and move on with their lives. The fact that most academics did continue teaching, often with online or blended learning techniques, ${ }^{14}$ suggests that they considered protestors' demand for no instruction as less influential than their own professional norms. While the responses of students to the protests is a matter for a separate paper, it must be noted that there was no consensus amongst the larger student body regarding the closure of teaching, with many silent or actively against the shutdown. Academics were therefore responding to different student groupings and constituencies themselves.

\section{Community: stakeholders}

The community of stakeholders involved in this activity system was diverse. At the pedagogical level, there were departmental colleagues who shaped academics' perspectives and practices regarding blended learning. At the managerial level there were faculty committees and institutional managers who provided policy guidance on teaching matters, especially in this time of crisis. At the teaching and learning level, there were students, protestors and tutors who were all directly affected by the pedagogical decisions made by the academics. At the disciplinary level, there were disciplinary peers at other institutions whose collective contributions to the field shaped academics' personal expectations concerning blended learning's potential role (i.e. whether it is normative or not). And, lastly, at the developmental level, there were support structures which could assist academics in going online.

\section{Division of labour}

The division of labour involved in UCT's blended learning activity system refers to academics who were producing blended learning content, the students who were consuming (and sometimes producing) it, the tutors who facilitated it, the third-party providers who sold it, and the professional staff members who supported it.

Particularly relevant were the tutors who play an important teaching role. In some cases, for example, academics reported that tutors embarked on "a 'pens down campaign', I think they call it. They refused to participate in it [blended learning] because they felt that it undermined the protest action and they didn't want any part of it" (Respondent 7). In addition, they argued that students' "unequal access [to the necessary technology to engage blended learning] might exacerbate the tensions in the student body, might exacerbate the very things that students are protesting against" (Respondent 7).

On the other side of this equation were the professional staff who showed academics how best to develop blended learning opportunities, including how to make their digital offering less bandwidth-intensive and easier to interact with on mobile phones.

\footnotetext{
${ }^{14}$ Other strategies were also used, including small classes held in cafes, lecturers' homes' etc.
} 
According to some of the academics, "In the absence of [professional staff] we would have been completely lost" (Respondent 3 ).

\section{Discussion: the key contradiction and its resulting tensions}

The elaboration of the activity system above has already revealed a fraught environment, comprising multiple, competing claims, opportunities and challenges. This discussion section focuses on the contradictions and tensions in light of the intended object of the system: to use blended learning to complete the curriculum in a time of protest. The primary contradiction shaping this activity was that of the opposing "rules" regarding teaching: on the one hand, protestors demanded that academics stop teaching (a demand that they verbalized and made manifest through the physical disruption of classroom teaching); on the other, the university management wanted teaching to continue in some capacity so that students and lecturers could complete the year's curriculum and exams in a timely fashion. The management's directive that academics should use blended learning to overcome the protestors' contradictory desires comprises its attempt to find a way to "resolve" (or at least bypass) the effects of this contradiction. As a result, this created a number of tensions for academics who not only had mixed feelings about the protests, but who worried that the broad use of blended learning would exacerbate digital inequality amongst the students, compromise the reputation of the university, and taint the future use of blended learning because of its association with the protests.

\section{Contradiction: academics were responding to opposing rules}

In the rules' node, it is clear that academics faced a number of competing formal rules, informal norms and non-formal demands, each made by different stakeholders. The university management formally requires face-to-face teaching in normal circumstances but called for blended learning during the time of disruption. The experience, for many academics, was not so clear as this, however, as Respondent 7 shared: "when these protests happen the university tend to communicate very badly with staff, very short-term notice of things and we are not really given any opportunity to engage ... There was lots of confusion around deadlines, moving of deadlines, which deadlines may be moved, so it is just, it is not a conducive environment at all I think for teaching and learning". Nonetheless, despite the confusion, the management remained an authority that academics had to respond to in some way.

Meanwhile, academics had their own teaching norms - often established informally through personal practice or peer engagement. The prevailing collegial institutional culture, allowing academics great autonomy in determining their own teaching strategies, made many instinctively unreceptive to the management's directive. But this wasn't just due to a style or sensibility, it was also based on what they felt was best for their students pedagogically. Many believed that blended learning was being foisted upon them as a "one-size-fitsall" response to the challenge of disruptions (Respondent 7).

In opposition to both of these approaches, protestors were calling for the suspension of all teaching activities - blended or not - until the end of the protests. However, while protestors were able to disrupt many classroom-based activities, they were less 
successful at interfering with academics' and students' online activities, thus offering the management, academics, and many students a kind of "fix" for that given situation.

Nevertheless, despite the continuation of teaching online, the protestors were still able to achieve their goal of ensuring that higher education would be free (for the poorer students) going forward. This was a direct result of their wide-reaching, coordinated and recurring protests, though not because UCT (or any other university) gave in to the protestors' demands. As public universities which rely to a great extent on state funding, this was financially an impossible demand to meet. Only the national government could provide such a resolution, which it eventually did. Thus, even though students directed their protest activities at the universities that they attended, in many ways their argument was with the state itself about how higher education is funded.

However, tough questions remain: Was the use of blended learning a betrayal of the fight for free decolonised education, given that the protestors demanded a cessation of all teaching to help meet this demand? Or was the deployment of blended learning a rational, practical response to meeting the needs of most students who, despite their own belief in the goals of the protests, still wanted to progress with their studies? And, given that it was ultimately only the state that could meet the demands of the \#FeesMustFall protestors, what responsibility did academics have for how the protests came about, unfolded, and were resolved, if any?

\section{Tension: academics had mixed feelings about the protests}

As mentioned above, most academics were sympathetic to the issues raised through the protests, while at the same time those interviewed were typically unhappy with the "political tools" used by the protestors to achieve their demands. Since all interviewed continued teaching by whatever means they could, they believed that there remained a strong moral claim that courses should be completed by the end of the year, for the sake of their students, many of whom needed to graduate.

Respondent 12 captured this prevailing ambivalence: "people don't like what is happening with the students or things like that but actually you have to find some way, whatever way is least offensive to you to find out what you need [to complete the courses]". There was also a view expressed that by using blended learning, disruptions were being normalised:

... the more we make it normalised, that we go online and stuff, the more we normalise the protest things, the more we say, 'OK, don't worry they are going to shut down the campus', and I kind of do feel that there should be a message that this is not normal and that more and more students should feel outraged at what they are experiencing. The fact that 200 students or so can hold the whole campus hostage is ridiculous, you know. And it is probably because we have been, we have normalised this protesting. (Respondent 12)

It was also clear that academics did not see students as a homogenous community, and that the protestors were not necessarily viewed as representing the views of all students. Academics tended to make a clear distinction between their support for the aims of the protests but not the actions of the protestors. 
Tension: academics feared blended learning would exacerbate inequality

Academics worried that any move to greater online learning would exacerbate digital inequality amongst the socio-economically diverse student body. This comment by Respondent 12 was typical: "The thing about it is that all these electronic things, which are great and they are marvellous, they benefit the wealthy students, they don't benefit the students who are struggling anyway". Their concern suggested that they would want a deeper examination of it before embracing it fully. As Respondent 16 said,

A lot of poor students don't have laptops and tablets and that sort of thing, so definitely the so-called digital divide came into play. So that was definitely the other big thing with blended learning, ... it was a creative solution I think to the problem that we found ourselves faced with, but I think that there were those points of resistance [regarding access and cost] that we need to think about carefully before we move forward with that as a kind of approach.

This came through in the many ways that academics tried to make sure that anything they shared digitally had the smallest file size possible (so as to not require too much data), be in the most widely available formats (Word, PDF, YouTube videos), and, where possible, offered as supplementary to the coursework, not as mandatory. Initiating blended learning demanded, for many academics, to be flexible in how they themselves responded, as Respondent 6 revealed: students "could hand in [printed materials] and they could slide it under my door if they came onto campus, [or] they could upload it as an assignment just by photographing their pages with a cell phone".

Yet others expressed concern that the use of blended learning went beyond digital exclusion to more profound forms of exclusion, believing that blended learning compounded an already inequitable and exclusionary cultural situation: "I think the university has definitely got a culture that is not conducive to including everyone and I think the blended learning makes it worse. If anything, it excludes people who are upset already" (Respondent 5).

In this context, blended learning may have helped overcome certain practical hurdles (classroom disruptions) while raising others (digital inequality). Further study on whether this was the actual result for students is yet to be concluded.

\section{Tension: academics worried that the broad use of blended learning might compromise the reputation of the university}

Another tension that emerged from the various forces and agents in this activity system was the sense that, if blended learning is adopted too comprehensively, the mission and ethos of the university would change for the worse. Blended learning, from this perspective, is breaking the agreement between university and student. As Respondent 16 summed up:

The second point of resistance is also from the students' side. So if we see teaching as being this traditional, walking into a classroom and engaging face to face, I think students very much see, in the kind of neo-liberal dispensation ... education as a kind of contract between the university and themselves. So it is a kind of product that they have paid for and they expect to receive it, so I think lots of resistance from students as well when classes are cancelled, that they are not essentially getting what 
they paid for as per the contract with the university and you know, whatever their parents paid for. So I think it has been very hard for students also to see these alternate forms of teaching as legitimate, because it is not.

This reinforces the quality concerns of Respondent 6 who, as mentioned above, worried about the "graduateness" of the students coming out the university because of all of the changes that were made to teaching and exams during the protests. After all, it was surely not the intention of the protestors, nor the management which responded with the blended learning intervention, to compromise the value of the university's degrees.

\section{Tension: academics had mixed feelings about blended learning itself}

As blended learning had not been widespread in this traditionally face-to-face university prior to the shutdowns, experience and familiarity amongst academics was extremely uneven. Those interviewed had at least some interest, but they were mindful of their peers, saying for example, "it has been quite difficult for staff who have not had any experience in the online space to suddenly be faced with putting the shift" (Respondent 2).

They noted that the mode was considered abnormal, such as Respondent 16, who said, "So the first point of resistance is from academics themselves because we are so used to the normal mode of instruction that it can be really hard to conceptualise teaching and learning in any other way than what we are completely used to because that is how we learnt".

There was also a view that blended learning should be properly planned for: "I tend to think that blended learning should be the beginning of the process rather than the response to an existing crisis .... I think because it was kind of so sudden, there wasn't any buy-in from lecturers genuinely unless they had kind of been doing it already and there wasn't really much buy-in from students" (Respondent 9).

Yet another put it more starkly: "I fear technology" (Respondent 3). Some of the ambivalence about blended learning did not seem directly related to the specific situation, and might have applied generally, such as the complaint that it "is so time consuming" for them. Similarly, the view that it is inappropriate for their particular discipline has been made more generally. As Respondent 4 bluntly stated, "You can't do pracs [practicals] in a fully online setting".

Thus, despite considering the option, some decided not to engage with it. Respondent 14 stated that, "I am a little bit more conservative than that, maybe because I have been taught through chalk and board and I still feel that there are certain things where the lecturer needs to see the response of the class".

In the light of these feelings about going online at all, and in a context where academics expect autonomy, there was unhappiness regarding what was expected of them: "I think we have got to be quite careful, you know. Staff deserve to be treated with such respect I think, you know, and to sort of suddenly force everyone to become an educational specialist overnight it is not easy" (Respondent 2). 
Tension: academics worried that blended learning would be tainted by its association with the protests

Comments from academics at the end of the third year of protests showed that blended learning was perceived negatively from being associated with student protests. As Respondent 15 said, "I think there was also just so much trauma and that has now been associated with this blended learning". Respondent 16 echoed, "the main issue of resistance was that the concept of blended learning emerged in reaction to a particular situation at UCT. I think that is the main reason there was that much resistance to it, blended learning kind of became this ugly word that the administration wants us to do because of protests".

As discussed above, the decision to direct academics to use blended learning to bypass the effects of the disruptions would have had the effect of short-circuiting the organic and necessary debates around blended learning amongst academics. Pressurised to use it, many of them engaged with blended learning without having the opportunity to explore it pedagogically and in line with educational and strategic goals. Ironically, this abrupt deployment may jeopardise its future use at UCT if academics and students view it as a compromised form of instruction. It remains to be seen whether that is the ultimate outcome of this intervention, but the ambivalence it suggests may indeed last for a long time.

\section{Conclusion}

In a situation of student protests and university shutdown, the use of blended learning as a strategy for completing the curriculum before exams was a particularly fraught choice, quite aside from the practical dimensions. The Activity Theory framework provides a way of unpicking the strands of pressure, conflict and ambivalence experienced by a selection of academics who used, or considered using, blended learning for this purpose. This particular group, despite their feelings about the aims of the student protests, their unhappiness about how the shutdowns were handled, and the constraints of their disciplinary practices, were all clear that they wanted to finish the curriculum, see the academic year through to completion within the calendar year, and have the students write exams.

Academics' actions were mediated by both technology and politics, with the use of technology being anything but neutral. For all the focus on the practical aspects, it was clear that blended learning was intrinsically political, raising ethical disquiet, and was part of a constellation of strategies and difficult decisions for engaging with the rapidly changing events as they unfolded. There was little room for reflection regarding the broader situation, and until the third year none at all for planning and forethought. It is of note that while changing their modes of teaching, academics were being simultaneously challenged in terms of content and pedagogy with calls to decolonise the curriculum having powerful effects. The ways that these challenges intersect with one another deserves serious scrutiny, one which merits scholarly attention in future.

In addition to surfacing the student perspective as captured in interviews, blogs and other methods at the time, it will also be important to pay attention to the role of learning technologists and academic development staff whose loyalties were sorely tested at this time, and who were at the forefront of the decision to provide 
blended learning options. Their position was a hub in the ecosystem of protests, shutdowns, student constituencies and non-hierarchical constellations, management and academics.

Given that these interviews were undertaken during or immediately after the disruptions of 2017, they capture an immediacy of academics' responses. With some time having passed, it would be worthwhile to ascertain how those events and challenges have changed pedagogy and practice, how academics review their choices of the time and what can be taken forward that was learnt from those turbulent times.

Finally, this study highlights the compromises and compromising position played by the technology itself, throwing into sharp relief the lack of consensus and clarity of what blended learning actually is when it affords and can be appropriated by such different agendas. In a digitally mediated age, blended learning potentially plays a unique role mediating what Mbembe (2015) describes as "the meeting of new, emerging antagonisms with old, unresolved ones."

\section{Acknowledgements}

The authors gratefully acknowledge the academics who agreed to be interviewed when they were under great pressure as well as the insightful reviewers.

\section{Authors' contibutions}

Laura Czerniewicz was responsible for conceptual framing and interpretation, Henry Trotter was responsible for analysis and Genevieve Haupt conducted interviews and undertook preliminary analysis. All authors have approved the final manuscript.

Funding

This research was funded by the Carnegie Corporation of New York.

\section{Availability of data and materials}

The data that support the findings of this study are available from Professor Laura Czerniewicz but restrictions apply to the availability of these data, which are not publicly available. Ethical clearance was obtained by the UCT Faculty Ethics Committee.

\section{Competing interests}

The authors declare that they have no competing interests.

Received: 3 June 2019 Accepted: 1 October 2019

\section{(2010)}

\section{References}

Adam, T. (2019). Digital neocolonialism and massive open online courses (MOOCs): Colonial pasts and neoliberal futures. Learning, Media and Technology 44(3): 365-380. Available at: https://doi.org/10.1080/17439884.2019.1640740.

Badat, S. (2016) Deciphering the meanings and explaning the South African higher education students protests of 2015-16. In Nyamjoh, F. (Ed.) Student and Scholar Protests in Africa Pax Academica. Dakar, Senegal: Codesria.

Bali, M. \& Caines, A. (2018). A call for promoting ownership, equity, and agency in faculty development via connected learning. Int J Educ Technol Higher Educ, 15, 46. https://doi.org/10.1186/s41239-018-0128-8.

Booysen, S. (Ed.) (2016). Fees must fall: Student revolt, decolonisation and governance in South Africa. Johannesburg: Wits University Press.

Bosch, T. (2016) Twitter activism and youth in South Africa: the case of \#RhodesMustFall, Information, Communication \& Society, 20(2): 221-232.

Boyd, D. (2016). What would Paulo Freire think of blackboard: Critical pedagogy in an age of online learning. Int J Crit Pedagogy, 7(1): 165-186 Retrieved from http://libjournal.uncg.edu/ijcp/article/view/1055/892.

CHE (Council on Higher Education). (2016). South African Higher Education Reviewed: Two Decades of Democracy. Pretoria: CHE. Available at: https://www.che.ac.za/sites/default/files/publications/CHE_South\%20African\%20higher\%20education\%2 Oreviewed\%20-\%20electronic.pdf

Chikane, R. (2018). Breaking a rainbow, building a nation: The politics behind \#MustFall movements. Johannesburg: Pan Macmillan.

Council on Higher Education, (2016). South African higher education reviewed: Two decades of democracy, Council on Higher Education, Pretoria.

Czerniewicz, L. \& Brown, C. (2009). A study of the relationship between institutional policy, organisational culture and elearning use in four South African universities. Comp Educ, 53(1): 121-131. https://doi.org/10.1016/j.compedu.2009.01.006. 
Czerniewicz, L. \& Haupt, G. (2018). Blended learning in challenging circumstances - The case of UCT. Presented at the Carnegie Foundation blended learning seminar, Ekurhuleni, South Africa, 1 June 2018. Available at www.siyaphumelela. org.za/documents/5c1234b7e354b.pdf

de Wet, T., van Rooyen, C., Frahm-Arp, M. \& Joshi, H. (2018). One tweak at a time: University of Johannesburg. Presented at the Carnegie Foundation blended learning seminar, Ekurhuleni, South Africa, 1 June 2018. Available at www. siyaphumelela.org.za/documents/5c1235670705c.pdf

DHET (Department of Higher Education and Training) (2018). Statistics on Post-School Education and Training in South Africa: 2016. Available at www.dhet.gov.za/DHET\%20Statistics\%20Publication/Statistics\%20on\%20Post-School\%20Education\%2 Oand\%20Training\%20in\%20South\%20Africa\%202016.pdf

Engeström, Y. (1987). Learning by expanding: An activity theoretical approach to developmental research. Helsinki: OrientaKonsultit.

Fitzgerald, P. \& Seale, O. (2016). Between a rock and a hard place: University management and the \#FeesMustFall campaign. In S. Booysen (Ed.), Fees must fall: Student revolt, decolonisation and governance in South Africa, (pp. 235-255). Johannesburg: Wits University Press.

Habib, A. (2019). Rebels and rage: Reflecting on \#FeesMustFall. Johannesburg: Jonathan Ball.

Hayes, S. \& Jandrić, P. (2014). Who is really in charge of contemporary education? People and technologies in, against and beyond the neoliberal university. Open Rev Educ Res, 1(1): 193-210. https://doi.org/10.1080/23265507.2014.989899.

Heher, J. (2017). Report of the Commission of Inquiry into Higher Education and Training to the President of the Republic of South Africa. Available at: www.thepresidency.gov.za/download/file/fid/1075

Hodes, R. (2016). Questioning 'fees must fall'. African Affairs, 116(462): 140-150

Hoover, D. M., Dopson, S. \& Drehobl, P. (2010). Working with local, state and federal partners to address health education needs of Hurricane Katrina evacuees in Houston: A CDC case study. American Journal of Health Education, 41(2): 124-126.

Jansen, J. (2017). As by fire: The end of the south African University. Cape Town: Tafelberg.

Kilfoil, W. (2018). Trends: Blended learning and \#FeesMustFall case studies. Presented at the Carnegie Foundation blended learning seminar, Ekurhuleni, South Africa, 1 June 2018. Available at www.siyaphumelela.org.za/ documents/5c122e708249a.pdf

Mackey, J., Gilmore, F., Dabner, N., Breeze, D. \& Buckley, P. (2012). Blended learning for academic resilience in times of disaster or crisis. Journal of Online Learning and Teaching, 8(2): 122-135.

Mbembe, A. 2015. "Decolonizing knowledge and the question of the archive." Lecture. May 2, 2015 at the Wits Institute for Social and Economic Research. Available at http://wiser.wits.ac.za/system/files/Achille\%20Mbembe\%20-\%2 0Decolonizing\%20Knowledge\%20and\%20the\%20Question\%20of\%20the\%20Archive.pdf.

Meintjes, A. (2018). The aftermath of \#FeesMustFall: An activity theoretical analysis of blended learning at the UFS. Presented at the Carnegie Foundation blended learning seminar, Ekurhuleni, South Africa, 1 June 2018. Available at www. siyaphumelela.org.za/documents/5c12353cd2888.pdf

Ngcaweni, W. \& Ngcaweni, B. (Eds.) (2018). We are no longer at ease: The struggle for \#FeesMustFall. Johannesburg: Jacana.

Potgieter, M., Pilcher, L. A., Tekane, R. R., Louw, I. \& Fletcher, L. (2018). Lessons learnt from teaching and learning during disruptions. In M. Schultz, S. Schmid \& G. Lawrie (Eds.), Research and practice in chemistry education. Singapore: Springer.

Ray, M. (2016). Free fall: Why south African universities are in a race against time. Johannesburg: Bookstorm.

Scheepers, D., Kriel, D., Nagel, L., Pretorius, G., Smart, A. \& Thukane, M. (2018). Use of blended learning during \#FeesMustFall 2016: University of Pretoria case study. Presented at the Carnegie Foundation blended learning seminar, Ekurhuleni, South Africa, 1 June 2018. Available at www.siyaphumelela.org.za/documents/5c123592d4988.pdf

Swartz, B. C., Gachago, D. \& Belford, C. (2018). To care or not to care - reflections on the ethics of blended learning in times of disruption. South African J Higher Educ, 32(6): 49-64

Tauson, M. \& Stannard, L. (2018). EdTech for learning in emergencies and displaced settings: A rigorous review and narrative synthesis. London: Save the Children. Available at https://resourcecentre.savethechildren.net/sites/default/files/ documents/edtech-learning.pdf.

Tekane, R., Louw, I. \& Potgieter, M. (2018). \#FEESMUSTFALL: Science teaching during student unrest. Alternation, 25(2): 161-180.

Trotter, H., Kell, C., Willmers, M., Gray, E. \& King, T. (2014). Seeking impact and visibility: Scholarly communication in southern Africa. Cape Town: African Minds.

Tull, S., Dabner, N. \& Ayebi-Arthur, K. (2017). Social media and e-learning in response to seismic events: Resilient practices. J Open, Flexible, Distance Learning, 21(1): 63-76.

UNESCO (2018). A lifeline to learning: Leveraging mobile technology to support education for refugees. Paris: UNESCO. Available at https://unesdoc.unesco.org/ark:/48223/pf0000261278.

\section{Publisher's Note}

Springer Nature remains neutral with regard to jurisdictional claims in published maps and institutional affiliations. 